\title{
Language Blogging Community: Fostering the Learning Attitudes and Writing Skills of EFL Students
}

\author{
Ming Huei Lin $^{1}$ \\ ${ }^{1}$ English Department, Tamkang University, Taiwan \\ Correspondence: Ming Huei Lin, English Department, Tamkang University, 151 Yingzhuan Road, Danshui Dist., \\ New Taipei City, Taiwan. E-mail: johnlinminghuei@gmail.com
}

Received: February 2, 2019 Accepted: February 28, 2019 Online Published: April 6, 2019

doi:10.5539/ijel.v9n3p1 URL: https://doi.org/10.5539/ijel.v9n3p1

\begin{abstract}
This paper empirically studies a group of first-year EFL college students in a blog-supported composition class in Taiwan. To improve their writing skills, the participants kept journal blogs within a language blogging community (LBC) where users could receive free help (e.g., corrections/comments) from native speakers regarding entries written in a second/foreign language (in this case, English). Students' writing skills and learning attitudes (anxiety about writing) were assessed (by multifaceted examination) before and after the classes. The results show that over the sessions the participants formed active blogging patterns and expressed themselves better, using more linguistic information. These encouraging signs echoed the students' improved compositional skills and reduced writing anxiety. The pedagogical suitability of blogging in EFL writing classes is discussed and topics are suggested for future studies.
\end{abstract}

Keywords: language blogging, blog-assisted language learning, EFL writing, learning anxiety

\section{Introduction}

Classroom blogging has long been considered a promising approach to teaching in language classrooms (cf. Halic, Lee, Paulus, \& Spence, 2010; Hung \& Huang, 2015a). The approach is popular in the specific field of teaching English as a second/foreign language (ESL/EFL) writing (Lin, Li, Hung, \& Huang, 2014) although blogs have also been used in teaching other skills, such as reading (Lee, 2015) and speaking (Huang, 2015; Hung \& Huang, 2015b). Many studies provide empirical support for using writing blogs in English classes (Kung, 2015). However, some researchers citing counterproductive cases have questioned its effectiveness in this context; it sometimes enhances student bloggers' anxiety over writing (e.g., Lin, Groom, \& Lin, 2013), hindering the development of their writing skills and learning attitudes (Lin, 2014). Additionally, the increased workload on teachers who manage class blogs has not hitherto been fully addressed (cf. Levy, 2009; Lin, 2016). Thus, blogging's effects are difficult to determine (Lin, 2016).

Given these inconsistencies and limitations, before blogs can establish a robust footing in ESL/EFL writing classes, additional research is required. One possible solution is to ask students to keep a blog journal explicitly for language learning. This overt goal, it is anticipated, would maintain the efficacy of blogging while addressing its hindrances and their possible causes. These ends are realised by involving learners in a language blogging community (LBC), that is, an online blogging platform on which everyone's aim is to exchange or learn language. Here the members blog in the second or foreign language being learnt, but support one another using their first language. These opportunities encouraged an experiment involving a group of EFL students in an intensive English composition class supported by an online language-blogging platform. Since no contrast group was recruited, the writing skills and learning attitudes of the participants were comprehensively examined before and after the experiment. The study addresses the research question whether keeping a blog journal in an online community with the specific purpose of language learning an effective approach for EFL students to learn writing.

\section{Literature review}

\subsection{Theoretical and Empirical Support for Blog Use}

The various effects of blogging are primarily ascribed to the nature of the blogosphere giving bloggers individual spaces to express themselves freely (Trajtemberg \& Yiakoumetti, 2011), in particular in written language. Thus, 
blogging is a suitable means for practicing writing. The specific character of a blog as an easily accessible online platform also increases readership with ample of interaction between the blog's writers and readers (Chen \& Brown, 2012; Lin et al., 2014). Receiving more attention received and more communicative interaction may together encourage student bloggers to persevere (Chen \& Brown, 2012). As Lin et al. (2013) and Lin (2015) conclude, the advantages may mutually reinforce themselves and thereby lead student bloggers to a positive cycle of writing improvement such as modern motivation theories describe (cf. Dörnyei, 2001; Dörnyei \& Hadfield, 2014; Dörnyei \& Ushioda, 2011).

In fact, much empirical evidence has suggested that classroom blogging is an effective approach to teaching writing. On the one hand, most student writers taught in a blog-supported classroom have reacted favorably to the approach (Arslan \& Şahin-Kız1l, 2010; Kung, 2015; Lin et al., 2014; Trajtemberg \& Yiakoumetti, 2011). On the other hand, the blogging approach has been reported to trigger interaction between readers and student writers (Miceli, Murray, \& Kennedy, 2010; Mompean, 2010), nurture the writer's sense of a community of practice (Kang, Bonk, \& Kim, 2011; Miceli et al., 2010), enhance learner motivation to write (Arslan \& Şahin-Kızıl, 2010; Lin, 2015; Sun, 2010), strengthen the self-efficacy of student writers (Lin, 2016), and ultimately successfully improve students' writing skills (Arslan \& Şahin-Kızll, 2010; Chen, 2016; Lee, 2015; Lin, 2015; Lin et al., 2014; Sun, 2010).

\subsection{Limitations of Classroom Blogging}

Despite its many endorsements, the actual pedagogical effectiveness of blogging in EFL/ESL writing classes has been challenged. First, while student improvements through blogging is unassailable, the gains may also come from the associated increase in the teachers' workload (cf. Levy, 2009), making the specific effects of blog use hard to determine (Lin, 2014, 2016). Resolving this issue is important because maintaining an active class blog is labor-intensive and appears sufficient drawback for certain teachers to ban educational blogs in their classes (Lai $\&$ Chen, 2011). Such maintenance includes the provision of technical support, managing the electronic content for all concerned, and, not least, meeting students' needs in learning development (cf. Hourigan \& Murray, 2010), given the constant and instant feedback/comments that students expect (Lin, 2012).

Contradictory findings in the literature on student learning performance also undermine the desirability of blog use in EFL writing classes. Many early studies (e.g., Chiao, 2006; Lin et al., 2013; Wu, 2008) consistently noted that student writers rarely produced active blogging patterns. Although such inactivity may stem from poor teacher supervision (e.g., monitoring/requiring student engagement) (cf. Chiao, 2006; Sun, 2010; Lin, 2012), Lin et al. (2013), finding similar results in a separate experiment, provide a striking explanation: blogging students were deeply inhibited by anxiety about writing. Specifically, Lin et al.'s students were described to have constant apprehension regarding peer and public criticism of the linguistic quality of their entries or the comments they left for others. The vicious cycle of trepidation about being ridiculed and avoidance behavior (i.e., blogging less) may explain why Chen's (2016) EFL students, after attending a blogging project, displayed less self-efficacy in writing than those enrolled in a conventional writing class. The same explanation may also account for the empirical findings of Lin (2014), who found that compared with those who kept traditional pen-and-paper journals, EFL student bloggers not only developed by no means superior writing skills but also were significantly less motivated to write after the blogging experience.

Lin et al. (2014), however, reasoned that those unfavorable outcomes may also have been caused by disregarding "the very nature of blogging as a form of online diary writing" (p. 423). As they observe, educational blogs were often treated as a forum for online discussion among peers, a platform for posting writing exercises, or a class portal for announcements. Forcing the inclusion of these activities in the blogging may undermine the potential effects of the blogging approach on students' writing development. In fact, by restoring the focus of blogging to online diary writing, Lin et al. found that the student bloggers became less anxious about writing than others writing pen-and-pencil journal entries and that they outperformed the latter in terms of writing skills.

While Lin et al. (2014) seem to have enhanced blogging effectiveness, here improvements in the blogging formula are sought. First, Lin et al. adopted an on-campus blog server whose audience was primarily restricted to students and teachers registered at the experimental site, thus delimiting the generally public nature of the blogosphere and leaving the potential of blogging indeterminate. Second, Lin et al. alleviated the teaching burden of using blogs, but did so by asking students to keep a blog journal entirely unaided, obviating suggestions or feedback. Given that linguistic skills were what Lin et al.'s students most desired to improve by joining the blog project, they still expect comments, guidance, or corrective feedback from someone able to offer them, such as teachers or advanced language users, regardless of the problems previously reported of keeping a public blog journal. Although this outcome sounds contradictory to the belief and practice of Lin et al., it is not 
entirely surprising since, as Mompean (2010) concludes, classroom blogging is after all not a "real life" practice but a pedagogical gambit. Highlighting this, however, the present writer is not suggesting a retreat. Instead, what is recommended is to redefine how blogging and its purposes can be introduced to ESL/EFL student writers such that student learning attitudes remain undamaged and blog teachers' workloads get no heavier.

\section{Methods}

\subsection{Participants}

This experiment, at a Taiwanese university, involved 24 first-year college students who attended a three-week composition course intended to help them develop organized paragraphs in different genres of English writing. The course occupied two 50-minute lessons on three consecutive days per week, and the teaching covered the development of topic sentences, supporting sentences, and concluding sentences, but not language use or vocabulary in general. The participants, mostly aged 18 , had diverse academic backgrounds, namely, majors in English (six females, two males), French (two females), German (two females), Japanese (three females), Russian (two males), Spanish (two females, one male), Business Management (one female), Computer Science and Information Engineering (one male), Educational Technology (one male), and Transformation Management (one male). Before this course, the participants had studied EFL for 8 to 10 years, and their proficiency mostly reached level A2 (10 students) and B1 (12 students) of the Common European Framework of Reference (CEFR) for languages; only two students had reached level B2.

\subsection{Treatment}

Before the experiment, the participants were introduced to the project's free blog server: Lang- 8 (http://lang-8.com) (Figure 1). Like typical blogs (e.g., Wix, Blogger), Lang-8 is an open platform on which Internet users can create accounts, publish entries online, make comments, and network with other users. However, unlike most blogs, Lang- 8 primarily serves as a language-exchange platform on which registered "users write in a [second/foreign] language and get [corrections/comments] from native speakers" (Massung \& Zhai, 2016, p. 168), focusing on writing skills. As Lin (2015) comments, it can offer this because of Lang-8's large membership (over 1,600,000 registered users as of December 2018) from many native-language backgrounds (over 90 different languages). Users can give corrective feedback or comments directly on one another's entries (Figure 2) through a pre-installed Lang-8 application (called Tracker). Lang-8's unique functionality and increasing membership relieves language teachers $\mathrm{f}$ the extra effort or time requirements of blog-supported classes reported in previous studies and also implement a live LBC, as in this project. 


\section{Lang-8}

\section{Let our community of native speakers support your language learning.}

A new language learning platform where native speakers correct what you write.

\section{Create an Account (Free)}

Sign Up With Twitter

\section{f Sign Up With Facebook}

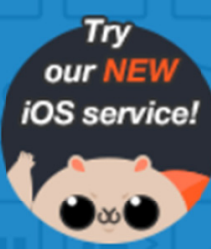

$\odot$ Or take our video tour

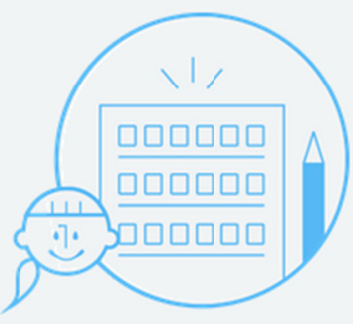

Post in the language that you are learning.

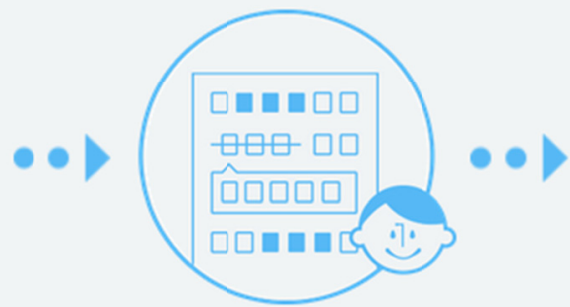

Native speakers correct your writing!

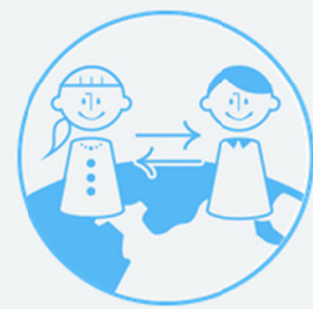

Return the favor by helping others learn your native language!

\section{G+1 1.5k Y Tweet Like 50,230 people like this. Be the first}

With native speakers from more than 190 countries and 90 languages to study, finding a language partner has never been so easy.

Figure 1. Lang-8 homepage 


\section{Start My Plan Again}

Aug 18, 2015 13:19

$$
\text { ( } 033 \square 101 \text {. English }
$$

It has been a long time since the last time I wert to gym with my friend. Both of us want to be in a nice shape before we enter the university. We started our plan for a few weeks, and it really worked! We were so glad to see our changes. Not only we can have a beautiful body shape, but also it does good to our health. And I feel that my face turned more flawless and rosy. But later, we got other things to busy with and didn't have time to continue the plan. Maybe it was better to say that we got lazy and felt tired to go to the gym regularly. Now, we have more time and both of us think it's time we started our plan again. I enjoy when I sweat a lot, it seems that I really try hard on exercising. My next goal is to run twenty minutes without taking a break. I know it's a piece of cake to many people, but to a person who doesn't even want to have PE classes in senior high school like me, it's really a challenge.

1. It has been a long time since the last time I went to gym with my friend.

( It has been a long time since the last time I went to the gym with my friend.

1. Both of us want to be in a nice shape before we enter the university.

- Both of us want to be in a nice shape before we enter the university.

We started our plan for a few weeks, and it really worked!

This sentence is perfect! No correction needed!

- We started our plan for a few weeks, and it really worked!

This sentence is perfect! No correction needed!

We were so glad to see our changes.

This sentence is perfect! No correction needed!

- Not only we can have a beautiful body shape, but also it does good to our health.

Not only we can have a beautiful body shape, but it is also good for our health.

\. And I feel that my face turned more flawless and rosy.

$\checkmark$ And I feel that my face turned became more flawless and rosy.

1. But later, we got other things to busy with and didn't have time to continue the plan.

But later, we got busy with other things and didn't have time to continue the plan.

- Maybe it was better to say that we got lazy and felt tired to go to the gym regularly.

- Maybe it was better to say that we got lazy and felt too tired to go to the gym regularly.

Now, we have more time and both of us think it's time we started our plan again.

This sentence is perfect! No correction needed!

I I enjoy when I sweat a lot, it seems that I really try hard on exercising.

$\checkmark$ I enjoy when I sweat a lot, it seems that feels like I'm really exercising hard.

or "I'm really trying hard." or "I'm giving a lot of effort."

My next goal is to run twenty minutes without taking a break.

This sentence is perfect! No correction needed!

I know t's a piece of cake to many people, but to a person who doesn't even want to have PE classes in senior high school like me, it's really a challenge.

This sentence is perfect! No correction needed!

Ahank you for your correction!

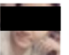

Figure 2. Snapshot of the Tracker function in Lang- 8 
After the introduction, the consenting participants created their personal Lang-8 account and were expected to begin an intensive blogging pattern of 10 journal entries during the project. Blog entries could be written daily or every other day on any subject they pleased. Students were also encouraged to read peer articles, comment on one another's work, and network with users other than peers. Because blogging formed part of their composition course, all such activities were tasks for the participants' free time. They were judged feasible because the participants claimed access to PCs, laptops, or smartphones,

Finally, because Lang- 8 was judged useful for a practicing LBC where many registered users could help one another in their own native languages, the instructor (the present writer) in this experimental project provided no corrective or other comments/feedback on his students' entries. This in turn allowed him to objectively judge whether the participants' improvements in linguistic features (e.g., grammar) were attributable to blogging efficacy.

\subsection{Writing Tests}

To evaluate student writing performance after the experiment, pre- and post-tests were administered. Each test was a 25-minute in-class paragraph-writing task in which the students wrote at least 120 words on a general issue in student life. In the pre-test, the participants wrote about the use of smartphones on campus, and in the post-test, about part-time jobs for students.

Both writing tests were assigned two marks by two trained English composition raters, not the researcher. Before assessment, the raters agreed on the criteria of the General English Proficiency Test (GEPT) writing rubric adopted for the task. The GEPT is a popular test in Taiwan launched in 1997 (www.gept.org.tw). Its writing section is assessed by a 5-band holistic rubric, with 1 indicating the lowest proficiency and 5 the highest. The scores generated by the raters were later examined using Pearson's $r$ for inter-rater reliability. The results revealed high agreement between the raters' marks (pre-test samples: $r=.73, p=.000$; post-test scores: $r=.76$, $p=.000$ ), ensuring the validity of the raters' scores for subsequent data analysis, for which the scores were averaged.

To assess more thoroughly, both the pre- and post-test compositions were analysed in two other ways. First, basic linguistic features in the writing samples - types and tokens of words-were counted. Second, the participants' command of grammar was assessed by linguistic error analyses counting errors per 100 words. Such measurement is needed to evaluate how well the design of the project's blogging platform allowed users to comment on other entries. Assessing the participants' grammatical proficiency in turn might generate further evidence of the effects of blogging, especially when linguistic features were not part of the main content taught in class.

\subsection{Questionnaire}

Previously, the student bloggers had experienced anxiety (Lin et al., 2013), which was claimed to impact negatively on their practice of blogging and observed to abate when the blogging formula was improved (Lin, 2014). However, anxiety has rarely been quantitatively investigated, particularly compared to factors such as motivation. In this regard, anxiety can be an important variable reflecting student writers' perceptions of the blogging experience, and studying anxiety can enrich the current literature on blog studies. Cheng's (2004) Second Language Writing Anxiety Inventory (SLWAI) was administered to participants before and after the experiment. SLWAI uses a highly reliable valid five-point Likert-scale questionnaire with three subscales that probe three essential components of L2 writing anxiety: one for Somatic Anxiety (SAS, seven items), one for Cognitive Anxiety (CAS, eight items), and one for Avoidance Behavior S (ABS, seven items). SAS measures people's perception of their physiological reactions to anxiety; CAS examines their mental perception of their anxiety, including negative views or concern about others' comments; and ABS measures avoidance behavior when anxious.

\subsection{Data Analysis}

The data collected from the writing assessments and the questionnaires were analysed using paired-sample $t$-tests to determine whether the treatment improved students' writing performance and attitudes to learning. To complement the inferential statistical results, a descriptive analysis of the word counts was conducted using WordSmith 5.0.

Student blogging activities were reported as well, to indicate actual student engagement in the experiment (cf. Lin, 2015; Lin et al., 2013), including the numbers of views, comments, and corrections the students received. Such descriptive reports are useful because as Lin (2015) comments, blogging patterns may give some idea of students' perceptions of blog-assisted language learning. In turn, this information may guarantee the validity of 
the LBC described here.

\section{Results}

\subsection{Learning Anxiety Toward Writing}

Table 1 reveals some significant differences between the entry and exit questionnaire outcomes. First, a statistically significant difference was found in the overall questionnaire $(t(23)=5.18, p=.000)$ with a substantial effect $(r=.73)$, suggesting that, in general, the treatments significantly lessened the student bloggers' anxiety. This change is supported by the statistical results of the underlying subscales (SAS: $t(23)=2.80, p$ $=.010$; CAS: $t(23)=4.63, p=.000$; ABS: $t(23)=4.06, p=.000)$, which were accompanied by great effects $(r$ $=.50 ; r=.69 ; r=.65)$. This outcome means that the treatment allowed the participants to write with physiological reactions, mental perceptions, and avoidance behavior that were considerably less anxious.

Table 1. Paired-sample $t$ tests for student learning attitudes

\begin{tabular}{lllllllll}
\hline Items & Test & $\mathrm{N}$ & Mean & $\mathrm{SD}$ & $d f$ & $t$ & $p$ & $r^{*}$ \\
\hline Overall Questionnaire & Pre-test & 24 & 65.83 & 12.75 & 23 & 5.18 & .000 & .73 \\
& Post-test & 24 & 59.29 & 10.49 & & & & \\
SAS & Pre-test & 24 & 20.50 & 4.67 & 23 & 2.80 & .010 & .50 \\
& Post-test & 24 & 18.71 & 4.02 & & & & \\
CAS & Pre-test & 24 & 25.42 & 4.44 & 23 & 4.63 & .000 & .69 \\
& Post-test & 24 & 22.67 & 4.20 & & & & .6 \\
ABS & Pre-test & 24 & 19.92 & 5.08 & 23 & 4.06 & .000 & .65 \\
& Post-test & 24 & 17.92 & 4.04 & & & & \\
\hline
\end{tabular}

Note. $*$ The effect size $\mathrm{r}$ was calculated using the equation $\mathrm{r}=\sqrt{\mathrm{t} 2} / \sqrt{ }(\mathrm{t} 2+\mathrm{df})$ (Rosnow \& Rosenthal, 2012).

\subsection{Writing Performance}

Students' writing performance also reflects improved attitudes to writing anxiety; they could write using more linguistic information than before the treatment (137.71 tokens and 85.75 types per article/person) (see Table 2). On average, each student produced 39.25 more words and 11.17 more types in the post-test. These increases are more noteworthy because they occurred in timed tests. They also signify that after joining a writing course featuring an LBC the students became more capable of expressing themselves in writing.

Table 2. Basic linguistic features in student writing samples

\begin{tabular}{lllllll}
\hline Items & Tests & $\mathrm{N}$ & Minimum & Maximum & Mean & SD \\
\hline Tokens & Pre-test & 24 & 99.00 & 191.00 & 137.71 & 22.85 \\
& Post-test & 24 & 129.00 & 251.00 & 176.96 & 31.62 \\
\multirow{2}{*}{ Types } & Pre-test & 24 & 61.00 & 108.00 & 85.75 & 11.84 \\
& Post-test & 24 & 81.00 & 152.00 & 96.92 & 16.02 \\
\hline
\end{tabular}

Table 3 supports this inference. A significant difference in student writing performance $(t(23)=-3.12, p=.004)$ was found between the pre- and post-tests, large in effect $(r=.55)$. This indicates that after the experiment, the participants statistically improved their overall writing skills substantially.

Table 3. Paired-sample $t$ tests for the overall writing test results

\begin{tabular}{|c|c|c|c|c|c|c|c|c|}
\hline Items & Test & $\mathrm{N}$ & Mean & SD & $d f$ & $t$ & $p$ & $r$ \\
\hline \multirow[t]{2}{*}{ Writing tasks } & Pre-test & 24 & 2.52 & .58 & 23 & -3.19 & .004 & .55 \\
\hline & Post-test & 24 & 3.04 & .72 & & & & \\
\hline
\end{tabular}

Table 4 also shows enhanced grammatical skills (from 13.68 errors per 100 tokens to 11.61), in a nearly significant improvement; the difference between the pre- and post-tests was only marginally statistical $(t(23)=$ $2.05, p=.052)$, with a medium-sized effect $(r=.39)$.

Table 4. Paired-sample $t$ tests for the writing qualities of grammar (Mean: errors per 100 tokens)

\begin{tabular}{|c|c|c|c|c|c|c|c|c|c|c|c|}
\hline Test & $\mathrm{N}$ & Total errors & Total tokens & Mean & Min. & Max. & SD & $d f$ & $t$ & $p$ & $r$ \\
\hline Pre-test & 24 & 449 & 3305 & 13.68 & 6.25 & 25.25 & .050 & 23 & 2.05 & .052 & .39 \\
\hline Post-test & 24 & 481 & 4247 & 11.61 & 4.23 & 17.16 & .037 & & & & \\
\hline
\end{tabular}




\subsection{Blogging Patterns}

The blogging patterns shown in Table 5 correspond to the previously reported improved anxiety avoidance behavior and endorse the validity of the LBC. On average, each participant posted 9.92 journal entries over the three-week project, collected 114.83 views ( 11.58 per journal entry), had approximately $50 \%$ of entries corrected (5.29 articles per person), and received 3.21 comments. This blogging frequency may have encouraged student learning and linguistic skills.

Table 5. Overview of student blogging patterns

\begin{tabular}{|c|c|c|c|c|c|c|}
\hline Student ${ }^{*} /$ Gender & CEFR & $\begin{array}{l}\text { Scores in } \\
\text { pre-/post-tests }\end{array}$ & Total entries & Views received & Entries corrected & Comments received \\
\hline $\mathrm{S} 1 / \mathrm{F}$ & A2 & $3.00 / 3.00$ & 10 & 157 & 10 & 4 \\
\hline $\mathrm{S} 2 / \mathrm{M}$ & A2 & $2.00 / 2.00$ & 10 & 116 & 4 & 3 \\
\hline $\mathrm{S} 3 / \mathrm{F}$ & A2 & $2.00 / 2.00$ & 10 & 87 & 4 & 2 \\
\hline $\mathrm{S} 4 / \mathrm{M}$ & A2 & $2.00 / 3.50$ & 10 & 126 & 6 & 3 \\
\hline $\mathrm{S} 5 / \mathrm{F}$ & B1 & $2.50 / 3.00$ & 10 & 118 & 6 & 1 \\
\hline S6/F & B1 & $3.50 / 4.00$ & 10 & 127 & 7 & 8 \\
\hline $\mathrm{S} 7 / \mathrm{F}$ & B1 & $2.00 / 2.50$ & 8 & 96 & 4 & 2 \\
\hline $\mathrm{S} 8 / \mathrm{M}$ & B2 & $2.50 / 3.00$ & 10 & 111 & 7 & 3 \\
\hline $\mathrm{S} 9 / \mathrm{F}$ & A2 & $2.50 / 3.00$ & 10 & 103 & 4 & 2 \\
\hline $\mathrm{S} 10 / \mathrm{M}$ & B2 & $1.00 / 4.00$ & 10 & 86 & 1 & 4 \\
\hline $\mathrm{S} 11 / \mathrm{F}$ & B1 & $3.00 / 4.00$ & 13 & 120 & 5 & 2 \\
\hline $\mathrm{S} 12 / \mathrm{F}$ & A2 & $2.50 / 4.00$ & 10 & 100 & 5 & 2 \\
\hline $\mathrm{S} 13 / \mathrm{F}$ & B1 & $3.00 / 3.00$ & 9 & 142 & 8 & 5 \\
\hline $\mathrm{S} 14 / \mathrm{M}$ & A2 & $3.00 / 2.00$ & 10 & 116 & 3 & 2 \\
\hline $\mathrm{S} 15 / \mathrm{F}$ & B1 & $2.00 / 2.00$ & 11 & 106 & 4 & 1 \\
\hline $\mathrm{S} 16 / \mathrm{F}$ & B1 & $2.00 / 3.00$ & 10 & 150 & 5 & 2 \\
\hline $\mathrm{S} 17 / \mathrm{M}$ & B1 & $3.00 / 4.00$ & 10 & 142 & 7 & 4 \\
\hline $\mathrm{S} 18 / \mathrm{F}$ & B1 & $3.00 / 3.50$ & 10 & 96 & 5 & 4 \\
\hline S19/F & A2 & $3.00 / 4.00$ & 10 & 89 & 5 & 2 \\
\hline $\mathrm{S} 20 / \mathrm{F}$ & A2 & $3.00 / 2.50$ & 9 & 162 & 9 & 11 \\
\hline $\mathrm{S} 21 / \mathrm{F}$ & A2 & $3.00 / 3.00$ & 10 & 102 & 3 & 0 \\
\hline $\mathrm{S} 22 / \mathrm{F}$ & B1 & $2.00 / 2.00$ & 9 & 106 & 4 & 4 \\
\hline $\mathrm{S} 23 / \mathrm{F}$ & B1 & $3.00 / 3.00$ & 9 & 101 & 7 & 4 \\
\hline $\mathrm{S} 24 / \mathrm{M}$ & B1 & $2.00 / 3.00$ & 10 & 97 & 4 & 2 \\
\hline Average & A2-B2 & $2.52 / 3.04$ & 9.92 & 114.83 & 5.29 & 3.21 \\
\hline
\end{tabular}

Note. *Participants are called S1 ... S24 to preserve anonymity.

\section{Discussion and Conclusion}

This study investigated the pedagogical value of a language blogging community supporting a Taiwanese EFL writing class. Multifaceted quantitative examinations yielded consistent results favoring the approach. After the treatment, the participants significantly improved their general writing skills, and felt less anxious about writing. Their blogging patterns also affirmed the feasibility and efficacy of a functioning LBC. The findings echo previous claims by Arslan and Şahin-Kızıl (2010), Chen, Liu, Shih, Wu, and Yuan (2011), Lee (2015), Lin (2015), Lin et al. (2014), and Sun (2010) that blogging-assisted language learning strengthens EFL students' writing skills and supports the early empirical evidence of learner attitudes improved by blogging (Arslan \& Şahin-Kızıl, 2010; Lin, 2015, 2016; Sun, 2010). The frequent blogging pattern reported here recalls observations by Chen and Brown (2012), who discern intensified interactivity between (blog) writers and readers, and supports the belief of Kang et al. (2011) and Miceli et al. (2010) that blogging reinforces the sense of communities of practice.

The significant lowering of anxiety among participants further justifies the methodology and blogging formula employed. That is, classroom blogging is by nature pedagogic (cf. Mompean, 2010). Improving students' writing skills by blogging journals not only fulfils the purpose of blogging as a form of journal-writing but helps diminish their concerns over being criticized for it. They also benefit by satisfying their expressed educational need of linguistic feedback (see Lin et al., 2014). In this regard, it may be claimed that combining these refined elements creates a relatively suitable and sensible way of using blogs for EFL purposes, developing students' learning. 
As this study shows, another merit of blogging in an LBC is to advance the existing blogging formula in the literature. Despite receiving no teacher supervision, comments, or feedback, believed to compromise the effectiveness of classroom blogging (e.g., Chiao, 2006; Lin, 2012; Sun, 2010), the present approach, insisting on frequent blogging, improved avoidance behaviour by removing writing anxiety. This outcome produced more objective evaluation of the strength of the blogging approach and suggests that it is effective.

Despite improved writing skills in general, one improvement was revealed as only marginally statistically significant, that of accuracy. To rigorous statisticians, this seems to constrain the blogging efficacy discussed above. However, grammar is after all a challenging area for many student writers (Lin et al., 2014) because it comprehends numerous linguistic aspects, such as the use of vocabulary for different parts-of-speech, collocations, tenses, and even punctuation marks, among many others. The full development of grammar skills usually takes months and sometimes many years. Therefore, given the improvement over such a short period (10 blog entries over three weeks), it may not be premature to claim that the gain of grammatical accuracy found here lends support to the blogging approach.

While the discussion has hitherto augmented the legitimacy of integrating an LBC into EFL writing classes, several aspects await further investigations before this prescription can be confidently adopted. First, the student writer's overall experience of blogging in such an online community has not been qualitatively examined here although the quantitative results have suggested the blogging approach suitable for EFL writing classes. A qualitative inquiry should also determine the underlying factors that empower students to learn writing in such a blog-supported writing context. In particular, probing student bloggers' in-depth perceptions/perspectives of the corrections and comments they receive on their journal entries would yield useful insights. Tackling this specific issue should help clarify the concerns raised regarding the language learner's view of non-teacher feedback. As Peng (2008) observed, student bloggers did not trust the quality of non-teacher comments. To a degree, Peng's finding reflects an early warning by Nelson and Murphy (1993), who cautioned that "[language] students who view the teacher as the 'one who knows' may ignore the responses of [others]" to their writing because they might not believe that peers are sufficiently knowledgeable to provide worthwhile feedback (p. 136). Thus, whether students would perceive feedback from native speakers differently is an interesting yet fundamental question, especially for blogging approaches similar to that examined here.

Second, although this study presents an effective method to decrease student blogger writing anxiety, further insight into the overall effectiveness of blogging on students' learning attitudes can be achieved from looking at the longitudinal development of learner autonomy. To date, little empirical evidence has suggested that blogging stimulates the autonomous development of students (e.g., Lee, 2011; Sun, 2010). Most data are based on the fact that students actively formed regular blogging patterns on their own schedules. For example, the blogging frequency observed in this study would be treated by certain researchers as evidence of learner autonomy. Although it is encouraging that a number of studies have expressed confidence in blogging's potential to boost autonomy, the validation of this assertion demands added empirical evidence. This question is particularly important given that participants in early blogging studies (e.g., Arslan \& Şahin-Kızıl, 2010; Trajtemberg \& Yiakoumetti, 2011) stopped engaging themselves in further blogging activities once the research projects concluded, regardless of whether their efforts had positive or negative results. It seems to be a common phenomenon that the learning activities of a subject/course end when the subject/course finishes. However, this outcome is unwelcome with respect to blog use considering that one of its purposes is to train student bloggers to become independent, self-directed autonomous learners, with or without teacher presence or course requirements. Therefore, an abrupt abandonment of blogging by student bloggers may connote scant learner autonomy. A long-term investigation is required.

Third, different from previous studies in which the experimental courses were semester-long or required (e.g., Chen, 2016; Kung, 2015; Lee, 2015; Lin, 2012), this research performed a case study on participants who volunteered for a short-term, intensive writing program. This may suggest that the student writers studied here had stronger determination or more enthusiastic learning attitudes regarding improvement to their compositional skills. Thus, they were probably prepared to put in the blogging practice that their teacher recommended and do so frequently. In addition, such learning characteristics may have nurtured the development of their learning attitudes during this experimental course and helped them overcome certain obstacles, such as reluctance to be mocked for their writing skills or a hesitancy to blog (cf. Chiao, 2006; Lin, 2014; Lin et al., 2013; Wu, 2008). Whether similar results can be found for learners in regular composition classes who blog in a similar language community would be a fruitful line of inquiry. Likewise, considering student learning styles and preferences when performing an experiment like this would advance our understanding of the effectiveness of blogging, particularly given that recent research (e.g., Lee, Yeung, \& Ip, 2016) has observed a meaningful correlation 
between certain learning styles and the use of computer technology for English language learning.

Finally, it must be acknowledged that even though this study included participants from various college majors, the sample came from a single experimental site. Moreover, the sample size was smaller than is generally suggested for quantitative inquiries (i.e., 30 individuals) (Dörnyei, 2007). These factors may limit the generalizability of the results. Similarly, no contrast groups were available from which to ascertain how far the study results were exclusively subject to blogging effects, since in-class writing instruction itself should also help students with certain compositional skills. Future investigations which consider these aspects should have much to contribute.

\section{Acknowledgments}

This article was written with funding support from Taiwan's Ministry of Science and Technology (MOST 104-2410-H-032 -051).

\section{References}

Arslan, R. Ş., \& Şahin-Kızıl, A. (2010). How can the use of blog software facilitate the writing process of English language learners? Computer Assisted Language Learning, 23(3), 183-197. https://doi.org/10.1080/09588221.2010.486575

Chen, J. C., \& Brown, K. L. (2012). The effects of authentic audience on English as a second language (ESL) writers: A task-based, computer-mediated approach. Computer Assisted Language Learning, 25(5), 435454. https://doi.org/10.1080/09588221.2011.606224

Chen, P.-J. (2016). Learners' metalinguistic and affective performance in blogging to write. Computer Assisted Language Learning, 29(4), 790-814. https://doi.org/10.1080/09588221.2015.1068813

Chen, Y. L., Liu, E. Z. F., Shih, R. C., Wu, C. T., \& Yuan, S. M. (2011). Use of peer feedback to enhance elementary students' writing through blogging. British Journal of Educational Technology, 42(1), E1-E4. https://doi.org/10.1111/j.1467-8535.2010.01139.x

Cheng, Y. S. (2004). A measure of second language writing anxiety: Scale development and preliminary validation. Journal of Second Language Writing, 13(4), 313-335. https://doi.org/10.1016/j.jslw.2004.07.001

Chiao, T. L. (2006, July). Application of blogging in EFL writing class: A case study. In Proceedings of the Fifth International Symposium on English teaching (pp. 336-344). Taipei, Taiwan: Crane Publishing.

Dörnyei, Z. (2001). Motivational strategies in the language classroom. Cambridge, England: Cambridge University Press. https://doi.org/10.1017/CBO9780511667343

Dörnyei, Z. (2007). Research methods in applied linguistics. Oxford: Oxford University Press.

Dörnyei, Z., \& Hadfield, J. (2014). Motivating Learning. New York, NY: Routledge. https://doi.org/10.4324/9781315833286

Dörnyei, Z., \& Ushioda, E. (2011). Teaching and researching motivation (2nd ed.). Harlow, England: Pearson Longman.

Fellner, T., \& Apple, M. (2006). Developing writing fluency and lexical complexity with blogs. The JALT CALL Journal, 2(1), 15-26.

Halic, O., Lee, D., Paulus, T., \& Spence, M. (2010). To blog or not to blog: Student perceptions of blog effectiveness for learning in a college-level course. Internet and Higher Education, 13, 206-213. https://doi.org/10.1016/j.iheduc.2010.04.001

Hourigan, T., \& Murray, L. (2010). Using blogs to help language students to develop reflective learning strategies: Towards a pedagogical framework. Australasian Journal of Educational Technology, 26(2), 209225. https://doi.org/10.14742/ajet.1091

Huang, H. C. (2015). From web-based readers to voice bloggers: EFL learners' perspectives. Computer Assisted Language Learning, 28(2), 145-170. https://doi.org/10.1080/09588221.2013.803983

Hung, S.-T. A., \& Huang, H.-T. D. (2015a). Video blogging and English presentation performance: A pilot study. Psychological Reports, 17(2), 614-630. https://doi.org/10.2466/11.PR0.117c20z6

Hung, S.-T. A, \& Huang, H.-T. D. (2015b). Blogs as a learning and assessment instrument for English-speaking performance. Interactive Learning Environments. https://doi.org/10.1080/10494820.2015.1057746

Kang, I., Bonk, C. J., \& Kim, M. C. (2011). A case study of blog-based learning in Korea: Technology becomes 
pedagogy. The Internet and Higher Education, 14(4), 227-235. https://doi.org/10.1016/j.iheduc.2011.05.002

Kung, F. W. (2015). Assessing an innovative advanced academic writing course through blog-assisted language learning: Issues and resolutions. Innovations in Education and Teaching International. https://doi.org/10.1080/14703297.2015.1108213

Lai, H. M., \& Chen, C. P. (2011). Factors influencing secondary school teachers' adoption of teaching blogs. Computers \& Education, 56(4), 948-960. https://doi.org/10.1016/j.compedu.2010.11.010

Lee, C., Yeung, A. S., \& Ip, T. (2016). Use of computer technology for English language learning: do learning styles, gender, and age matter? Computer Assisted Language Learning, 29(5), 1033-1049. https://doi.org/10.1080/09588221.2016.1140655

Lee, L. (2011). Blogging: Promoting learner autonomy and intercultural competence through study abroad. Language Learning \& Technology, 15(3), 87-109.

Lee, S. Y. (2015). Joining the 'literacy club': When reading meets blogging. ELT Journal, 69(4), 373-382. https://doi.org/10.1093/elt/ccv030

Levy, M. (2009). Technologies in use for second language learning. The Modern Language Journal, 93, Focus Issue, 769-782. https://doi.org/10.1111/j.1540-4781.2009.00972.x

Li, Y. (2000). Assessing second language writing: The relationship between computerized analysis and rater evaluation. Review of Applied Linguistics, 127-128, 37-51. https://doi.org/10.1075/itl.127-128.02li

Lin, M. H. (2012). Blog assisted language learning in the EFL writing classroom: An Experimental study. Unpublished Doctoral dissertation, University of Birmingham, Birmingham, UK.

Lin, M. H. (2014). Effects of Classroom Blogging on ESL Student Writers: An Empirical Reassessment. The Asia-Pacific Education Researcher, 23(3), 577-590. https://doi.org/10.1007/s40299-013-0131-8

Lin, M. H. (2015). Learner-centered blogging: A preliminary investigation of EFL student writers' experience. Educational Technology \& Society, 18(4), 446-458.

Lin, M. H. (2016). Effects of language blogging on Taiwanese EFL student writers: A case study. Paper presented at 2016 International Conference on Applied Linguistics \& Language Teaching. Taipei, Taiwan.

Lin, M. H., Groom, N., \& Lin, C. Y. (2013). Blog-assisted Learning in the ESL Writing Classroom: A Phenomenological Analysis. Educational Technology \& Society, 16(3), 130-139.

Lin, M. H., Li, J. J., Hung, P. Y., \& Huang, H. W. (2014). Blogging a journal: changing students' writing skills and perceptions. ELT Journal, 68(4), 422-431. https://doi.org/10.1093/elt/ccu032

Massung, S., \& Zhai, C. (2016). Non-native text analysis: A survey. Natural Language Engineering, 22(2), 163186. https://doi.org/10.1017/S1351324915000303

Miceli, T., Murray, S. V., \& Kennedy, C. (2010). Using an L2 blog to enhance learners' participation and sense of community. Computer Assisted Language Learning, 23(4), 321-341. https://doi.org/10.1080/09588221.2010.495321

Mompean, A. R. (2010). The development of meaningful interactions on a blog used for the learning of English as a Foreign Language. ReCALL, 22(3), 376-395. https://doi.org/10.1017/S0958344010000200

Nelson, G. L., \& Murphy, J. M. (1993). Peer response groups: Do L2 writers use peer comments in revising their drafts? TESOL Quarterly, 27(1), 135-141. https://doi.org/10.2307/3586965

Peng, Z. Y. (2008). A study of blogging for enhancement of EFL college students' writing. Unpublished master dissertation, National Tsing Hua University, Taiwan

Pham, V. P. H., \& Usaha, S. (2016). Blog-based peer response for L2 writing revision. Computer Assisted Language Learning, 29(4), 724-748. https://doi.org/10.1080/09588221.2015.1026355

Rosnow, R. L., \& Rosenthal. R. (2012). Beginning behavioural research: A conceptual primer (7th ed.). Englewood Cliffs, NJ: Pearson.

Sun, Y. C. (2010). Extensive writing in foreign - language classrooms: A blogging approach. Innovations in Education and Teaching International, 47(3), 327-339. https://doi.org/10.1080/14703297.2010.498184

Trajtemberg, C., \& Yiakoumetti, A. (2011). Weblogs: a tool for EFL interaction, expression, and self-evaluation. ELT Journal, 65(4), 437-445. https://doi.org/10.1093/elt/ccr015 
Wu, W. S. (2008). Using blogs in an EFL writing class. In S. Priya (Ed.), Netlingo: The metamorphosis of language (pp. 86-99). Hyderabad, India: The Icfai University Press.

\section{Copyrights}

Copyright for this article is retained by the author, with first publication rights granted to the journal.

This is an open-access article distributed under the terms and conditions of the Creative Commons Attribution license (http://creativecommons.org/licenses/by/4.0/). 